dimension. This facilitates precise homograft size selection that takes into account graft size availability and recipient's ascending aortic diameter.

We found this technique to be very simple. Without adding significant crossclamp time, it has the potential to prevent complications that may be extremely difficult to repair after completion of the coronary buttons and distal anastomoses, when the proximal suture is first tested under realistic pressure and hemodynamic conditions. This is to the best of our knowledge the first report of this technique.

\section{References}

1. Yankah AC, Pasic M, Klose H, Siniawski H, Weng Y, Hetzer R. Homograft reconstruction of the aortic root for endocarditis with periannular abscess: a 17-year study. Eur J Cardiothorac Surg. 2005;28:69-75.

2. Musci M, Weng Y, Hubler M, Amiri A, Pasic M, Kosky S, et al. Homograft aortic root replacement in native or prosthetic active infective endocarditis: twenty-year single-center experience. J Thorac Cardiovasc Surg. 2010;139:665-73.

3. Oechslin E, Carrel T, Ritter M, Attenhofer C, von Segesser L, Kiowski W, et al Pseudoaneurysm following aortic homograft: clinical implications? Br Heart J. 1995;74:645-9.

4. Nowicki ER, Pettersson GB, Smedira NG, Roselli EE, Blackstone EH, Lytle BW Aortic allograft valve reoperation: surgical challenges and patient risks. Ann Thorac Surg. 2008;86:761-8. e2.

\title{
Straight bronchial stent placement across the right upper lobe bronchus: A simple alternative for the management of airway obstruction around the carina and right main bronchus
}

\author{
Yun-Hen Liu, MD, Yi-Cheng Wu, MD, Ming-Ju Hsieh, MD, and Po-Jen Ko, MD, Tao-Yuan, Taiwan
}

\section{Supplemental material is available online.}

A variety of techniques have been described for stent placement in airway obstruction around the carina and the right main bronchus. These techniques use the silicone Y-stent, the double Y-stent, or an open "window" toward the right upper lobe (RUL) ${ }^{1,2}$ However, there is still no clear consensus on the optimal management of patients in this category. We describe 2 patients who were successfully treated with the simplified straight Dumon stent (Novatech, Grasse, France).

\section{CLINICAL SUMMARY}

Patient 1 was a 33-year-old woman with a 7-year history of pulmonary tuberculosis. The patient had stenosis at the right main bronchus (RMB) and RUL bronchus and underwent multiple bronchoscopic interventional procedures (electrocoagulation and cryosurgery) without clinical improvement.

\footnotetext{
From the Department of Surgery, Chang Gung Memorial Hospital at Linko, Chang Gung University, TaoYuan, Taiwan.

Disclosures: Authors have nothing to disclose with regard to commercial support.

Received for publication Feb 11, 2010; accepted for publication June 6, 2010; available ahead of print July 15, 2010

Address for reprints: Po-Jen Ko, MD, Department of Surgery, Chang Gung Memorial Hospital and Chang Gung University, No. 5, Fu-Shing Street, Guei-Shan Shiang,

Tao-Yuan, Taiwan 333, R.O.C (E-mail: foreverairmail@gmail.com).

J Thorac Cardiovasc Surg 2011;141:303-5

$0022-5223 / \$ 36.00$

Copyright (C) 2011 by The American Association for Thoracic Surgery doi:10.1016/j.jtcvs.2010.06.015
}

Chest radiographs showed complete collapse of the right lung. Bronchoscopy revealed a cuticular membrane lesion $(1 \mathrm{~cm})$ below the carina that completely obstructed the RMB. Computed tomography revealed severe distortion and narrowing of the RUL bronchi. Under general anesthesia, the blunt tips of Dumon scopes were used to manipulate and dilate the obstructed region of the RMB. The obstructed segment of bronchus was then opened, the normal airway size was achieved, and a number 14 Dumon stent $(14 / 30 \mathrm{~mm})$ was introduced over the stricture segment to maintain a patent airway. Chest roentgenogram showed good lung expansion with atelectasis of the RUL on the day after surgery. At 2 weeks post-surgery, the bronchoscopy revealed a good and patent airway without granulation and stent migration. The improvement in respiratory performance was dramatic after stent placement. The patient was discharged in good condition 2 days after surgery and was able to resume work 2 weeks after surgery. The patient did not experience any further complications related to stent placement during the follow-up period at 17 months post-stent placement (Figures 1 and E1, $A$ ).

Patient 2 was an 82-year-old man with right main bronchial chondroid hamartoma who presented with a 3-month history of progressive cough and intermittent shortness of breath. Chest computed tomography scans showed a masslike lesion in the right hilar region with distortion and stricture of the right main and RUL bronchi. Bronchoscopic evaluations revealed a mass that obstructed the RMB and extended along the RMB and down into the intermediate bronchus. The patient refused to undergo conventional airway reconstruction. With insertion of the rigid bronchoscope under general anesthesia, the stricture over the trachea was 

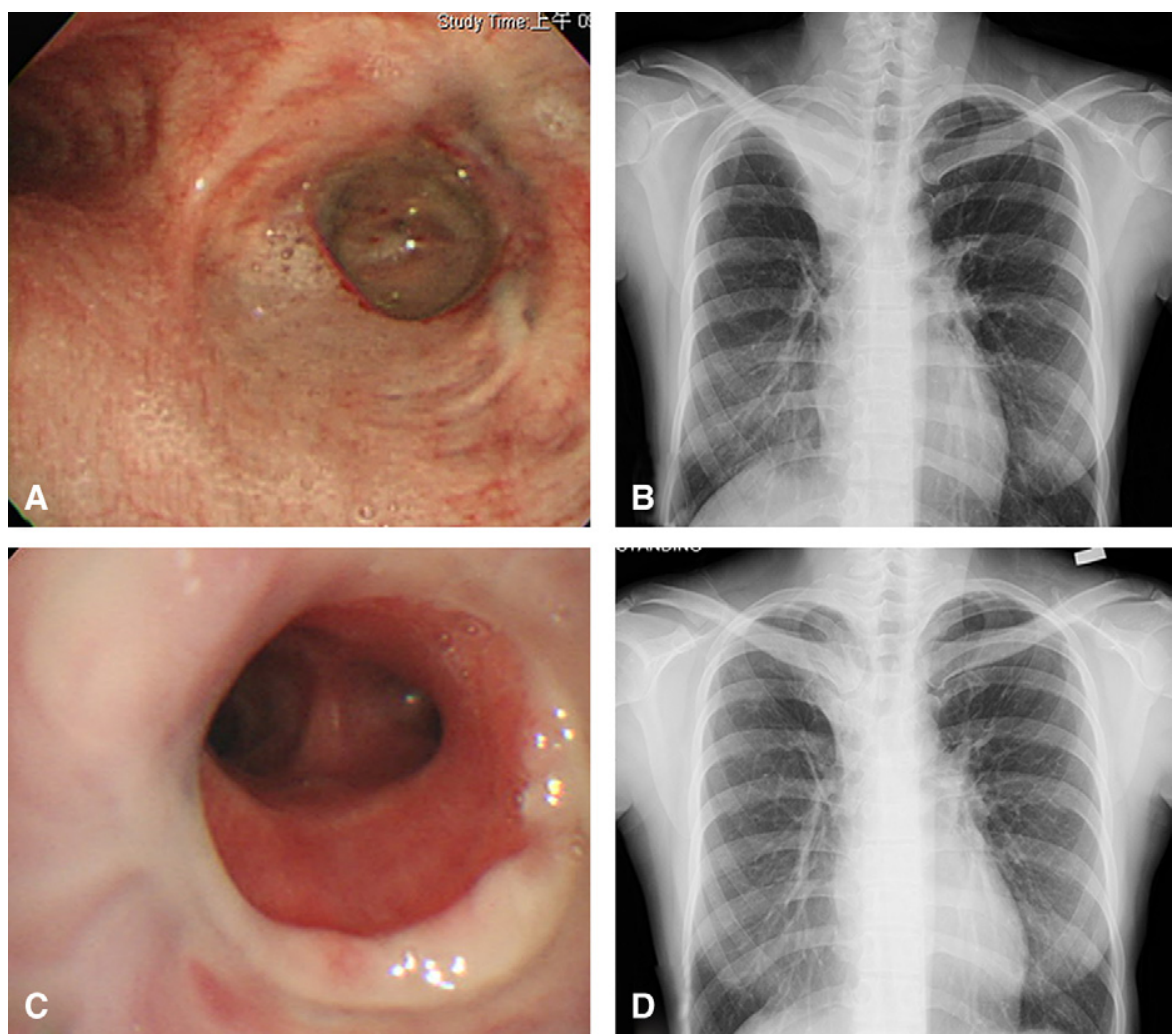

FIGURE 1. A, Bronchoscopy revealed complete obstruction of the RMB. B, Good lung expansion with atelectasis of the RUL after Dumon stent insertion (Novatech, Grasse, France). C, Patent middle and lower lobar orifice after Dumon trachea stent placement. D, Chest radiography 1 year after stent insertion shows full expansion of the right lung.

dilated, the RMB tumor was partially removed with a mechanical coring technique (by engaging the tumor lesion with the tip of the Dumon scope and debriding with biopsy forceps) to improve airway patency, the distance of stricture segment was measured, and the stent size was determined. A Dumon stent $(14 / 30 \mathrm{~mm})$ was inserted to maintain patent airway, with the distal limb placed $1 \mathrm{~cm}$ proximal to the bifurcation of the right lower lobe and right middle lobe bronchus. The respiratory performance of patient immediately improved after stent placement. The patient was discharged 3 days postoperatively with stable respiratory status. Further bronchoscopic study revealed granulation tissue with lumen obstruction $(40 \%)$ at the region of the distal stent end 2 weeks later. However, the postoperative course was uneventful and resulted in a satisfactory respiratory recovery after stent placement. At 6 weeks after surgery, bronchoscopy showed a greatly improved bronchial lumen. The patient was treated by daily respiratory humidification. He has not experienced any further respiratory problems 8 months after stent placement (Figures 2 and E1, B).

\section{DISCUSSION}

There are many different treatment modalities for managing major airway obstruction resulting from tracheal inflammatory diseases or neoplasm. Resection of the stricture portion with end-to-end anastomosis is the most common surgical treatment option. The use of stent placement to relieve airway obstruction is a minimally invasive alternative to open repair and is widely accepted by many physicians and patients.

Reported complications of airway stent placement include stent displacement, granuloma formation, and mucus impaction. Several studies have been conducted on the management and prevention of granulation complications in stent placement. For example, Hsieh and colleagues ${ }^{3}$ reported 2 patients with glottic stenosis after stenting who were successfully treated with a microdebrider. Gaissert and colleagues ${ }^{4}$ reported recurrent subglottic stenosis after stent insertion and claimed that substantial motion of the subglottic region during coughing or breathing predisposed the patient to granulation complications. Furthermore, our series evaluated the relation between stent-to-vocal fold distance and severity of granulation complications and found that a stent-to-vocal fold distance of $10 \mathrm{~mm}$ was a critical distance for critical granulation complication. ${ }^{5}$ All these data indicate that the quality of treatment depends on the management and prevention of complications. An experienced physician, combined with a delicate and simplified surgical technique, is required for managing complications of airway obstruction. 

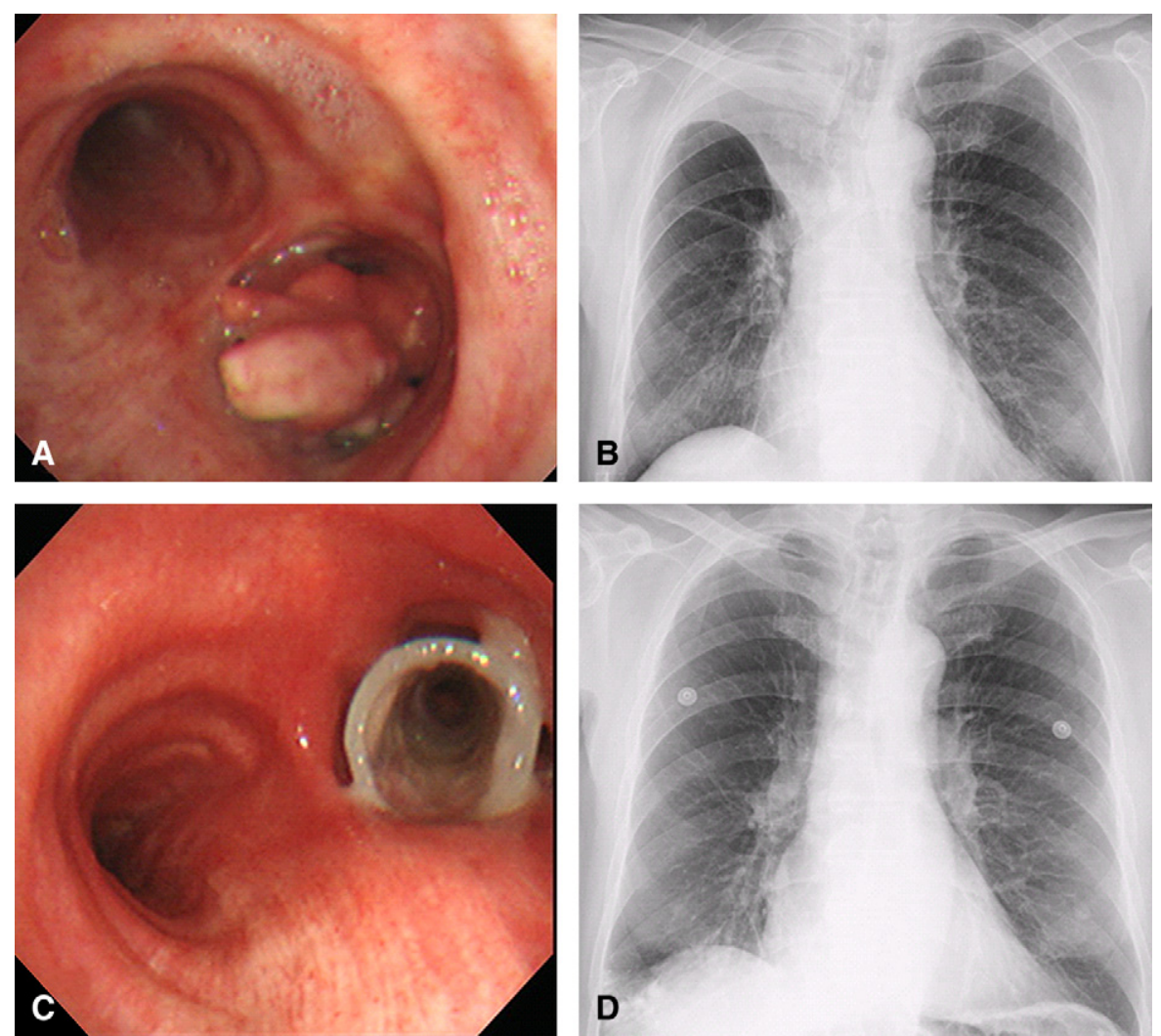

FIGURE 2. A, Chondroid hamartoma over the RMB. B, Good lung expansion with atelectasis of the RUL after Dumon stent insertion. C, Patent airway lumen after Dumon trachea stent placement. D, Chest radiography 3 months after stent insertion shows full expansion of the right lung.

Although pulmonary infection is a major concern when positioning a silicone stent to occlude the right upper lobar bronchus, it did not occur in both patients because of the complete collapse of the RUL after stent placement. As in the present patients, creation of a "window" in the stent toward the RUL runs the risk of airway fire and ingrowth of granulation tissue through the window of the stent. However, placing a carinal Y-stent between the RUL bronchus and the bronchus intermedius requires a meticulous surgical technique and high standard of surgical training.

\section{CONCLUSIONS}

This investigation described the successful placement of a straight Dumon stent in 2 cases of airway obstruction around the carina and RMB (occlusion of the lobar orifice and collapse of the RUL). Given the good outcome of the alternative treatment in both patients in the present study, we believe that the technique presented may be useful for treating airway stenosis in this subset of patients.

\section{References}

1. Oki M, Saka H, Kitagawa C, Kogure Y, Mori K, Kajikawa S, et al. Double Y-stent placement for tracheobronchial stenosis. Respiration. 2010;79:245-9.

2. Peled N, Shitrit D, Bendayan D, Kramer MR. Right upper lobe 'window' in right main bronchus stenting. Eur J Cardiothorac Surg. 2006;30:680-1.

3. Hsieh MJ, Liu YH, Yueh YS, Ko PJ. Use of microdebrider in glottic stenosis following airway stenting. Eur J Cardiothorac Surg. 2006;30:388-90.

4. Gaissert HA, Grillo HC, Wright CD, Donahue DM, Wain JC, Mathisen DJ. Complication of benign tracheobronchial strictures by self-expanding metal stents. J Thorac Cardiovasc Surg. 2003;126:744-7.

5. Ko PJ, Liu CY, Wu YC, Chao YK, Hsieh MJ, Wu CY, et al. Granulation formation following tracheal stenosis stenting: Influence of stent position. Laryngoscope. 2009;119:2331-6. 




A Pre-stent placement

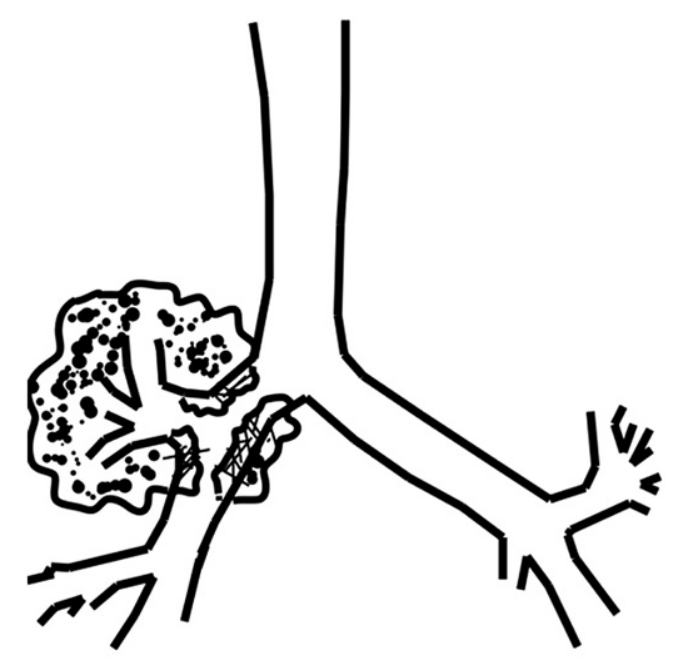

B Pre-stent placement

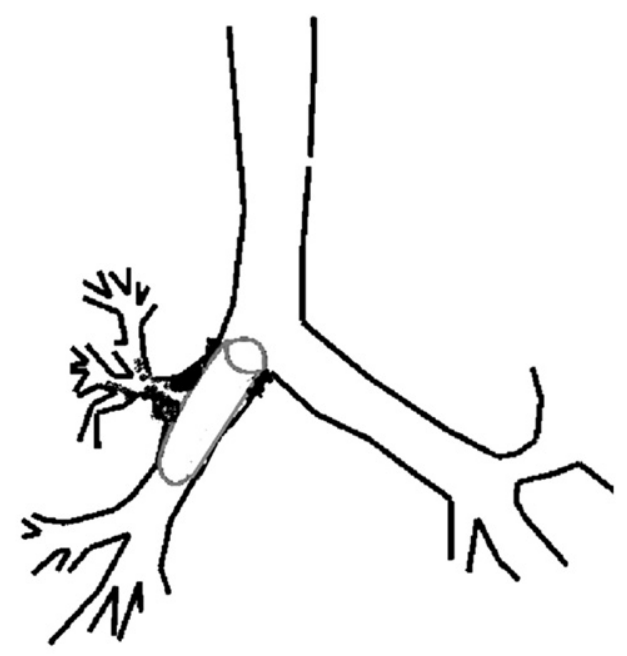

Post-stent placement

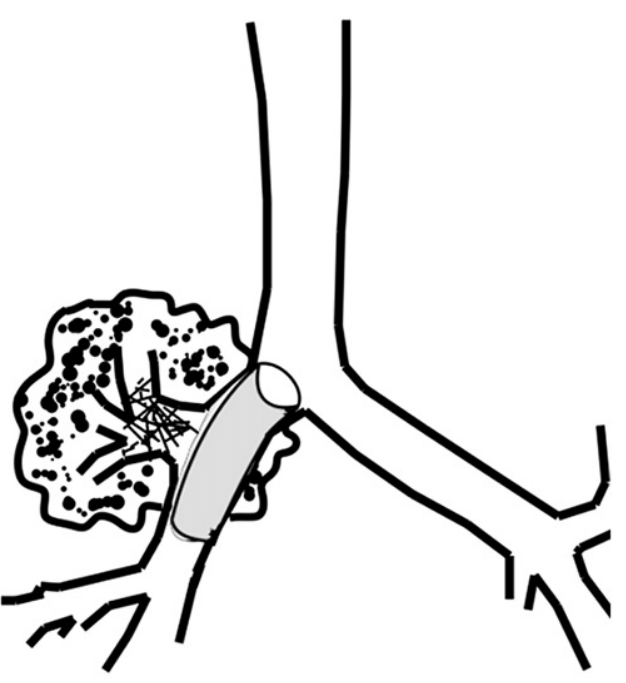

Post-stent placement

FIGURE E1. A, Schematic diagram before and after stent placement in patient 1. B, Schematic diagram before and after stent placement in patient 2. 